\title{
CURRENT CONCEPTUAL APPROACHES FOR ASSESSMENT OF THE PROCESS OF AGEING AND OLD AGE
}

\author{
Vanina Mihaylova, ${ }^{1}$ Dimitar Shopov, ${ }^{2}$ Iliya Bivolarski, ${ }^{3}$ Adolf Alakidi, ${ }^{4}$ Kristina Kilova ${ }^{5}$
}

\begin{abstract}
Ageing should be considered not only as an increase in the number of elderly and old people in their absolute and relative numbers, but also as a unity of the transformations of the lifecycle, with an emphasis on: later retirement, prolonged period of good-quality life, an active approach towards the process of retirement and differentiation of the category of "fourth age". The general preparation for old age has earned a new appeal in the contemporary societies. Motivation of the old people for activity - both physical and intellectual - is of great importance for the better survival of the old age and long life in good health, supported by realized well-being and feeling of joy from life. In this aspect the study of both risk and protective factors for human health (in a salutogenetic perspective) becomes increasingly fundamental. The issue of population at an advanced age has definitely been considered as an independent subject since the beginning of the $21^{\text {st }}$ century. Moreover, the society perceives it as an essential basis for further progress and flourishing of the mankind. In this sense the demographic strategies treating the problem need to address it in a new positive way, with different and positive attitude, accepting the population-related failures and anxiety and turning them into challenges and advantages.
\end{abstract}

JEL Classification Numbers: I3; DOI: http://dx.doi.org/10.12955/cbup.v5.1014

UDC Classification: 614.1

Keywords: healthy ageing, well-being, illness, disability, models of ageing, salutogenetic

"We live as long as God decides. But there is a significant difference whether we spend our old age miserably or well and meaningfully; a good physician can definitely contribute to this."

Goethe

\section{Introduction}

With these words Goethe, in the beginning of $19^{\text {th }}$ century concedes to the physicians the main responsibility for solving the problems of ageing and old age. He had not presumed that this burden would be assumed by the entire society. In the past century the average expectation of life almost doubled and the number of old people sharply increased.

The first signals of ageing of the population date back from the 1960s. The global society is already older than ever before in human history. Europe is the region in the world with the oldest population. At the same time it is assumed that research in the field of ageing on this continent has considerably fallen behind in comparison with the USA.

Ageing of the population on the Old Continent can be attributed mainly to two major demographic tendencies - decrease in birth-rate and increase life expectancy. This process creates a fundamental problem of complex nature - social, economic, psychological, medical, etc.Experts from the World Health Organization have established the that the stages typical of the second half of the human life are: medium age (maturity) - 45-59 years of age; advanced age - 60-74; old age - 75-89; long-living persons (macrobiots) -90 and over.

In many countries at least $10 \%$ of the population belongs to the group of people over the age of 65 (Bassuk et al, 1999). In the following decades the developed countries will likely witness a sharp increase in the actual and relative numbers of old people, while doubling the number of those over 65, and probably tripling (possibly even quadrupling) the number of people over the age of 85 . World Trade Organisation and the World Bank include ageing of the population among the future problems of highest priorities for the developing countries (Kumar and Steinmann, 1998). Currently about one fourth of the population in our country is over 60 , and the fraction of society over the age of 65 is bigger than $15 \%$.

\footnotetext{
${ }^{1}$ Faculty of Public Health, Medical University Sofia, Medical University Plovdiv, Bulgaria, vanina_delfi@abv.bg

${ }^{2}$ Faculty of Public Health, Medical University, Plovdiv, Bulgaria, shopov_d@abv.bg

${ }^{3}$ Department of General and Clinical Pathology and Forensic Medicine, Medicine Faculty, Medical University, Plovdiv, Bulgaria, iliya_bivolarski@abv.bg

${ }^{4}$ Medical Student in $6^{\text {th }}$ year, Medicine Faculty, Medical University Sofia, Bulgaria, delfi921@abv.bg

${ }^{5}$ Medical University - Plovdiv, Bulgaria, Faculty of Public Health, k_kilova@abv.bg
} 


\section{Psycho-emotional well-being for healthy ageing. General provisions}

The main societal challenges since the end of XX century have been maintenance of health and a good quality of life of the ageing population. For 60-year-old people, it could be expected that at least one fourth of their remaining years will be spent with a disability, including of psychogenic nature. According to Bretschneider and McCoy (1987), Isaacs (1992), Shah (1998), the age at the beginning of the deteriorating health could be increased faster than the rate of extension of human life due to the "compression of the sick-rate", i.e. a shorter period of illness and disability, reduction of untimely death and good health almost until death.

The long-term tradition in medical ethics confirms that the real objective of medicine is to contribute to the increase in patients' well-being. The psycho-emotional well-being and the possibility of overall healthy life are influenced by a relatively limited number of incurable conditions whose incidence is associated with ageing. An elderly person is no longer able to overcome their withdrawal from their habitual functions in their former social environment. Only a fast return to the typical social environment could prevent the unfavorable course of events. It should be noted that the main objective of medical treatment in old age is not necessarily the elimination of a disease, non-progression is often deemed sufficient. Other factors might prove to be more beneficial, such as maintenance of the habitual home environment, social relations and contacts, the life outside institutions; the perspectives for the future. This is so because health in old age can no longer be defined as a lack of any disturbances (of physical, psychological or social nature), but as an individual's potential to manage and to live with such disturbances.

In the contemporary dynamic world an individual, especially an elderly one, faces extremely difficult situations in life. The intensity of the experience opposite to well-being - the spiritual discomfort - is explained by Higgins et al. (1987) through their theory of discrepancies in the self-consciousness and the ego, differentiating conflicts in three varieties. In this way, the feeling of being rejected, which often and even inevitably accompanies old age according to Maslow (2001), is the key to many other events such as intrusive desire for gaining back love, development of defence mechanism, accumulation of hostility and other negative motivating conditions. In this sense the human ability for building "new structures" is of great importance and becomes a prerequisite for imitativeness and originality of one's image. The popular so-called "repertory grids" (Popova, (1993), creating readiness to search for an adequate response and adaptation mechanisms to stressful situations, and establishment of which is unique to the individual, appear to be of utmost importance, and at the same time the effectors of the increase in psycho-emotional well-being.

\section{The concept of "old age" and its successful reception}

If we make an attempt to summarize the viewpoint of leading authors with respect to the definition of the concept of old age, it is basically reduced to the following: an individual is as old as is his adaptation ability, i.e. the adaptive potential and speed of adaptation towards certain situations and their changes (Fink, 1987), (Schutz, 1980). Ageing cannot be interpreted as an illness. If the functional parameters of the thirty-year-old people are conditionally indicated with the initial value of $100 \%$, then within the framework of the reverse process, i.e. of regression or attenuating functions, the different values are reduced, affecting the heart, blood circulation, respiratory system, secretory system, etc. And as long as this regression is measured in physiological parameters, it can clinically remain unrevealed during the overall process of ageing. On the other hand, the reduced adaptation abilities lead to decreased resilience. In this sense we can talk about intrinsic predisposition to diseases leading to higher susceptibility to diseases (Bock, 1989).

This expected increase in the "predisposition" to diseases may provoke different reactions in the individual so that the health, well-being and overall capability could be preserved until reaching advanced age.

Preconditions for "successful reception" can be:

- Prophylactic medical checks

- Prevention of risk factors

- Personal hygiene and maintenance of the muscle tone

- Rational nutrition 
- Optimal clothing, especially in transitional seasons, for prevention of adverse effects of atmospheric changes and temperature fluctuations

- suitable home environment

- Maintenance of interpersonal contacts

- Physical and mental independence

- Established structured daily regime, in which activities and rests alternate at reasonable intervals.

Therefore the environment and lifestyle contribute to a large extent to healthy ageing and are prerequisites for the psycho-emotional well-being, the main determinant for the content living in the third stage of life. The ability of the individual to make changes in this direction is determined by the social and cultural context of their life, including personal choices, access, availability, information and income. Environmental factors, such as housing and air and water quality, which are fundamental for health, are not always satisfactory or acceptable.

Healthy ageing includes social, as well as physical and psycho-emotional well-being. Decisive factors are the social framework and policy which enable elderly individuals to realize their potential and achieve optimal health.

Application of scientifically substantiated approaches for infiltration in the personal theory of the elderly individual's inner worlds is envisaged with a view to achieve efficiency given the struggle of risk factors, as well as ratification and development of protective personal models of salutogenic nature (Mihaylova and Lyochkova, 2012).

\section{Deficit models of ageing and their overcoming}

Sociological surveys show prevalence of various specific negative age-related stereotypes such as (Schutz, 1987), (Smith, 1994):

- Advanced age is inversely proportional to the working capacity/capability

- Old people do not manage strain well

- Elderly individuals have been burdened with enough work, strain and hardship already; they should be allowed to just enjoy their life.

These so called deficit models of ageing describe the public status of the elderly people with the key phrases: deprived of role functions, and reduction of the ability for establishing new social relations, connections and contacts. In this way the situation of the older generation is presented in a distorted manner. This feeling of being damned has a negative impact on their behavior. According to this conception differing from the contemporary understanding, the elderly people are directed towards incorrect and inactive behaviour, even though they are able to perform many versatile and meaningful activities. The extremely drastic definition of the third stage of life by using the term "retirement" is nonsensical since it leads the elderly individuals to inactivity and condemns them to permanent free time. As a rule, life after retirement passes without any social structure because the society has not defined the role of the elderly person (Dunn et al., (1999). A similar risk exists mostly with reference to people of lower social status. This eventuality has been very successfully described by the American author Mulford in his book "Lit up by death" in 1938: "The capability of the old person decreases only because of the fact that he has been told that it should decrease with ageing" (Schutz, 1989).

It is ascertained that in the economically underdeveloped countries the elderly remain economically and socially productive even after retirement, for a long period of time (Krassen Covan, 2003), (Popova, 1993). According to Pichora-Fuller (2003), prevention of the psycho-emotional decline and promotion of the functional independence of elderly people is the key objective of modern geriatrics. This opinion is based on the circumstance that the interval of increased life span is divided into "active continuity" and "dependent continuity of life." The concept is entangled with the vision of the above-quoted compression of sick-rate ensuring healthy ageing. With some justification, Evans (2002) supports the opinion that preventive strategies aimed at extension of the active part of life at the expense of reduction of the period of functional dependency before death is one of the most 
fundamental objectives of the modern medicine and psychology.

Along with observed biological modifications and the increased susceptibility to diseases and psychiatric disorders, there has not been proven a general decrease in the mental capacity in the elderly (Bassuk et al., (1999), (Glass et al., (1999). Most affected and slowed down are the quick readjustment and reaction in resolving complex and combinational tasks, in situations requiring fast involvement of the analytical systems and concentration. However, the intellectual qualities requiring update of available and accumulated experience and knowledge are constantly preserved, independent and unaffected by the old age (Bickel, 1998), (Fortinsky et al., (2003).

It should be taken into consideration that the majority of people over 60 years of age passively accept the proposal for early retirement. They are not prepared to oppose, although they are complete masters of the potential of their capability, but lack information about the particular tasks and activities which could fill up their daily life. Insurmountable feeling of emptiness occurs, leading to depression, often followed by alcoholism or "escape to sickness" (Engelhard, 1986). Gerontological studies show that in the post-professional period only a well-structured daily routine guarantees social contacts and involvement. Free time, though not filled with duties, should be actively distributed and used with careful consideration in order to avoid boredom or dissatisfaction. It can be surely stated that efficiency can be preserved in the old age if the elderly people are motivated and cooperate for this. It should be kept in mind that the strongest motivation in human behavior is not the reasonable contemplations but the socially substantiated impulses (Clark et al., (1997), (Freund and Riediger, 2001).

Reasonably ageing people start looking for new roles and tasks which could completely satisfy their need for both mental and physical activity even before retirement. The assistance of new role functions in this search is a priority of the contemporary social policy.

\section{Two dimensions of old age}

\section{Old age as a chance}

From the point of health promotion, old age, even if it is accompanied by a disease or disability, should be regarded as a chance. Based on the possibility for comparatively optimal utilization of the available capacity for work, the following key phrase may be considered valid for the seventh decade of human life: "I should always consider the things I can still do and not the things I cannot do any more."

The above mentioned old age stereotypes also appear in case of chronic diseases. They affect mostly people who have in the course of their lives identified themselves with their professions, their personal successes and careers, with responsibility and power, i.e. qualities which fade away pretty fast upon retirement (Bassuk et al., (1999), (Engelhard, 1986). If favorable preconditions are set, the elderly individual remains independent and competent, i.e. manages their life and does not need care and service. But if they feel stifled by problems of any type - financial, social, housing, cultural or healthrelated, even the most insignificant event may lead to deterioration of their well-being; they feel (and according to the cognitive theory are) ill (Thomae, 1971), (Young, 2004). These short notes should confirm the unsoundness of the existing biased statements that old age presupposes obstinacy, rigidness, restricted mobility, unwillingness for establishing social contacts, deep absent-mindedness, non-commitment and inactivity. They should be replaced by categories such as unchanged capacity for work and readiness for acquisition of knowledge, independence, experience and competence. Elderly people are free from the pressure of doing a certain, possibly unwanted activity and have obligations which are without deadlines; they possess free time, i.e. advantages which can be related to the concept of advanced age (Schutz, 1987), (Tokarski and Schmitz-Scherzer, 1987).

\section{Health value}

Sociological surveys show that values such as subjective feeling of good health, satisfaction with life, independence, freedom, meaningful role in the society, family, and other are outlined as important (Parker et al., (2001). At the same time, the impact of social environment on health is also taken into consideration, for example income, sex, age, education and profession. The lifestyle is connected with the chances in life which provoke a desire for equalization of the health chances.

The cultural and personal specifications related to health are also considered. Studies indicate that 
health is not always the most important goal in life for people, including the elderly. Health norms and needs often give way to other goals in life, such as personal happiness, favorable living conditions, even the ability to travel, experience adventures, etc. (Ruffing-Rahal and Wallace, 2000). Despite that, in most European countries health and its maintenance stand high on the scale of the value systems of individuals, including those over the age of sixty, while disease prevention occupies a middle level. On the other hand, one's own behavior with regard to health and also the ability to correct harmful behavioral deviations, is very low especially in the elderly. It is pointed out that the attitude towards health in the advanced age should not be expressed as permanent anxiety with regards to one's own health and well-being. In correspondence with the concept of salutogenesis, health does not exist in itself and there are differences in its manifestation during certain time intervals (Mihaylova and Lyochkova, 2012).

The main social threat of old age is related to the breakup of the family and transition to an independent and insolated way of life. The return to the patriarchal relations typical of the $19^{\text {th }}$ century, and in our country until the first half of the $20^{\text {th }}$ century is impossible. The efforts are directed towards the increase and diversification of the forms of communication between the generations and finding new models of co-existence in contemporary architectural solutions -flats designated for that purpose or other family residences. Groups and associations for old people who put to front their priorities and values - self-protection and solidarity - have lately been formed. The category of the so called "young elderly person" is outlined as a unit of observation. Moreover, it is supposed that they dispose of multiple competences which can be used meaningfully and efficiently even in this inactive period of life. In this way the desire of most elderly people to bear personal responsibility for their vital activity is achieved. Mutual assistance is also covered - this is the basis for development of initiatives, both professional and social, at an advanced age.

\section{References}

Bassuk, S., Glass, T.A. \& Barkman, L.F. (1999). Social disengagement and incident cognitive decline in community dwelling elderly persons. Anuals of internal medicine, 165-173.

Bickel, H. (1998). Der Versuch am Menchen und seine eithische Problematik. Medizin, Etnos und soziale Verantwortungen. Bock, H. E. (1989). Arztliche Ethik am Krankenbett aus internistischer Sicht. Stuttgart: Sicht.

Bretschneider, J.G. \& N.L. McCoy. (1987). Sexual interest and behaviour in normal 80- to 102-year-olds. Arch Sex Behav, 109-129.

Clark, F., Azen, S.P., Zemke, R., Jackson, J., Carlson, M. et al. (1997). Occupational therapy for independent living older adults. A randomized controlled trial. JAMA, 1321-1326.

Dunn, A.L., Marcus, B.H., Kampert, J.B., Garcia, M.E., Kohl, H.W.\& Blair, S.N. (1999). Comparison of lifestyle and structured interventions to increase physical activity and cardiorespiratory fitness: a randomized trial. JAMA, 327-334.

Engelhard, D. V. (1986). Kulturhistoriesche und sozialpsychologische Voraussetzungen in: Mit der Krankheit Leben: Grundlagen und Perspektiven der Copingstruktur des Patienten. Verlag fur Medizin Fischer, 107 -149.

Evans, J. (2002). Succsessful aging and well-being: self-rated compared with Rowe and Kahn. Gerontologist (United States), 725-726.

Fink, U. (1987). Der neue Generationenvertrag. Die Zeit, Nr.13, 5.

Fortinsky, R.H., Kuchel, G. A., Coll, P.P. . (2003). Promoting healty and successful aging in everyday clinical practice. Conn Med (United States), 67.

Freund, A.M., Riediger, M. (2001). What I have and wath I do: The roll of resource loss and gain throughout life. Applied Psichology. An International Review, 370-380.

Glass, T. A., Leon, C.M., Mardtoli, R.A., Berkman, L.F. (1999). Population based study of social and productive activities as predictors of survival among elderly Americans. BMJ, $478-483$.

Higgins, E., Klein, R., Strauman, T. (1987). Self - Discrepansies: Distinguiscing Among Self-States, Self-State Conflicts and Emotional Vulnerabilities. In Self and Identy (Psychosocial Perspectives) (pp. 173-187). New York: Chichster.

Isaacs, B. (1992). The challenge of geriatric medicine. Oxford: Oxford Medical Publications.

Krassen Covan, E. (2003). The study of comparative gerontology. Health Care Women In (United States), 24(4), 267-268.

Kumar B.N. \& Steinmann, H. (1998). Ethics in International Management. Berlin: de Gruyter.

Maslow, E. (2001). Motivation and personality". Kibsa, 50-62.

Mihaylova, V.,\& Lyochkova, M. (2012). Salutogenesis: the end of the road or new perspectives? Journal of Social medicine, 2/3, 18-22.

Parker M. W., Fuller G.F., Koenig, H.G. (2001). Soldier and family wellness across the course: a developmental model of successful aging, spirituality, and health promotion. Part II. . Mil Med (United States), 166(7), 561-570. 
Pichora-Fuller, M. (2003). Cognitive aging and auditory information processing. Int J Audiol (Canada), 42 Suppl 2, 26-32. Popova, S. (1993). Personality and health . Jusastour, 72-78.

Ruffing-Rahal, M., Wallace, J. (2000). Successful aging in a wellness group for older women. Health Care Women Int (United States), 21(4), 267-275.

Schutz, R. (1980). Freizeit: Freude oder Fluch im Alter? Vortrag am Schleswig - Holstein -Tag, 146.

Schutz, R. M. (1987). In Alter und Krankheit (p. 37). Munchen.

Schutz, R. (1989). "Der alte Mensch in Gesundheit und Krankheit - Etische Probleme”. In Ethik im Alltag der Medizin., Herausgeber D.V. Engelhard, Berlin. Springer Verlag.

Shah, E. (1998). Greater - "Attempts must be made to promote positive roles for elderly people". BM Journal, 148.

Smith, W. (1994). Fitness for older people. BMJ, 1230 -1230.

Thomae, H. (1971). Die Bedeutung einer kognitiven Personlichkeitstheorie fur die Theorie des Alterns. Gerontol, 4,8,-15.

Tokarski, W., Schmitz-Scherzer, R. (1987). Alter und Krankheit, Urban Shwarzenberg. In R. Schutz, Altagsprobleme und Freizeitsverhalten alterer Menschen (pp. 114-187). Munchen: Verlag.

Young, H. C. (2004). Healthy aging for older women. Nurs Clin North Am (United States) 39(1), 131-143. 